\title{
The Value of Big Data Culture in the Strategy of Cultural Giant
}

\author{
Wang, Yuan-Xu \\ School of Marxism, Xuzhou Medical University, Xuzhou 221004, Jiangsu, P. R. China \\ email: xuyuanwang2007@126.com
}

Keywords: Big Data Culture; the Strategy of Cultural Giant; the Value

\begin{abstract}
To implement the strategy of cultural giant and build a powerful socialist nation, it is necessary to strengthen the cultivation of big data culture, so that the concept of big data culture will be closely integrated with our socialist culture. Starting with proposing and discussing the significance of the strategy of cultural giant, this paper probes into the value of big data culture in the strategy of cultural giant, and clearly points out that its national strategy entails the support of big data culture, which is integral to maintaining the advancement of socialist culture and to promoting the scientific elements of Chinese culture.
\end{abstract}

\section{Introduction}

Building a socialist cultural giant is a major strategic decision made by the CPC central committee from the overall perspective of the cause of socialism with Chinese characteristics. By expounding the strategy of cultural giant and its significance, this paper puts forward and elaborates this national strategy needs the support of big data culture, which is integral to maintaining the advancement of socialist culture. Big data culture is the requisite for improving the scientific elements of Chinese culture.

\section{The formulation and significance of the strategy of cultural giant}

\subsection{The formulation of the strategy of cultural giant}

\subsubsection{The process of formulation of the strategy}

In November 2011, the "decision" adopted by the sixth Plenary session of the 17th CPC Central Committee pointed out: "strengthening the soft power of the national culture, carrying forward the Chinese culture, and striving to build a socialist cultural power." This was the first time our country formally put forward the goal of building a socialist cultural giant.

In November 2012, the report of the 18th national congress of the communist Party of China further proposed: "to construct a cultural giant, we must persist in the development of socialist culture with Chinese characteristics." In October 2017, general secretary XI Jin-ping proposed the goal of cultural construction in the new era in the 19th CPC national congress report, namely adhering to the development of socialist culture with Chinese characteristics, stimulating the vitality of innovation and creation of national culture, and construct a socialist country with powerful culture.

\subsubsection{The background for the formulation of the strategy}

From the domestic perspective, the strategy conforms to the trend of historical development, in terms of the following aspects. Firstly, it is the inherent requirement of the continuous development of China Road; secondly, it is the inevitable requirement of the law of cultural development; thirdly, the strategy of cultural giant is the objective requirement of the development of Chinese culture[1].

From the international perspective, the strategy is base on China's cultural development, in terms of the following aspects. Firstly, the strategy of a cultural giant it is a prerequisite for world peace and development; secondly, it is motivated by an urgent need to promote the soft power; thirdly, it is a realistic need to maintain cultural security. 


\subsection{The significance of the strategy of cultural giant}

Firstly, it is conducive to enriching the connotation of the socialist system with Chinese characteristics; secondly, it helps to better meet the cultural needs of the people; thirdly, it is beneficial for China to be integrated into the world and open to the world; fourthly, it is conducive to the realization of the great rejuvenation of the Chinese nation.

\section{The support of big data culture to the strategy of cultural giant}

\subsection{Big data culture is a new driving force for the transformation and development of cultural industries}

Firstly, big data culture will transform such factors as material, technology, talent, and capital, which will exert a profound impact on the organizational model of social division of labor, and can promote the intensive innovation of the mode of production of enterprise culture; secondly, big data culture will promote the intensive integration of cultural production elements, network sharing, efficient utilization and cooperative development, which will change the production mode and operation mechanism of traditional cultural enterprises and raise the level of cultural and economic development; thirdly, big data culture can speed up the innovation of business model, give birth to many new cultural forms, and gradually become a new power to stimulate the growth of cultural enterprises in the field of Internet.

\subsection{Big data culture is a new way to drill the government's cultural management ability}

Firstly, big data culture can reveal the connection which can not be elaborated by traditional cultural management techniques, which could promote the opening and sharing of government cultural data, stimulate the fusion of cultural undertaking data and the integration of cultural resources, improve the ability of analyzing government cultural data, and provide new means for effectively dealing with complex cultural problems; secondly, under the guidance of big data culture, through the establishment and improvement of cultural database, the management and innovation of cultural data can be promoted to form a scientific mechanism for government to make decisions by relying on cultural data; thirdly, big data culture will drive the progress of the government's cultural management concept to adapt to the cultural system and undertakings, and gradually realize the modernization of the government's cultural management ability.

\subsection{Big data culture is a new opportunity to strengthen the influence of Chinese culture}

Firstly, under the guidance of big data culture, we can take advantage of the large scale of Chinese cultural data, improve the quality of cultural data and its application level, and exploit the potential of cultural data to the greatest extent; secondly, big data culture can give full play to the fundamental role of cultural resources, effectively maintain the data sovereignty of the Internet space, protect the cultural security of the country, and enhance the core competitiveness of national culture.

\section{Big data culture is the internal requirement to maintain the advancement of socialist culture}

\subsection{Big data culture enriches connotation for advanced culture}

\subsubsection{Contents of advanced socialist culture}

Firstly, the ideology is guided by Marxism; secondly, "New Youth with Four Virtues" is taken as the fundamental goal in the training of socialist citizens; thirdly, the development is oriented towards the modernization, the globalization and the future; fourthly, nationality, scientific nature and popularity are maintained as basic characteristics; fifthly, the core content not only absorbs the patriotism and collectivism in traditional Chinese culture, but also involves socialist ideology and morality. 
4.1.2 Big data culture as the new representation of advanced culture in the field of science and technology

Big data culture, as frontier culture of science and technology, contains scientific and technological knowledge, scientific methods, scientific thinking and scientific spirit, which are the spiritual achievements formed in the process of people's understanding and transformation of the world, as well as the cultural achievements of human beings. Since the 21 st century, information technology has achieved unprecedented development. Based on computer, cloud computing, network and communication technology, big data technology boosts contemporary technological revolution with powerful data storage and processing functions[2]. This revolution has brought new concept and lifestyle to people, which has laid a solid foundation for the diffusion of advanced culture and remarkably promoted its development.

\subsection{Improving advanced culture construction through big data culture}

Firstly, big data industry creates the material foundation for advanced culture construction. With data as the core resource, it will exploit the value of data through the collection, processing, analysis, application and the display; secondly, big data technology provides important support for the spread of advanced culture. To meet the cultural needs of individual differentiation and achieve accurate diffusion, a large amount of data can be used to analyze the individual cultural preferences, instead of simply focusing on diffusion. Instead, more attention is paid to each individual recipient.

\section{Big data culture is the requisite for improving the scientific elements of Chinese culture}

\subsection{Big data culture helps to keep orientation of socialist advanced culture}

As an advanced culture, big data culture has the characteristics of sharing and opening, which can not only stimulate the creativity of the whole nation's culture, improve the soft power of national science and technology culture, but also enrich the connotation of advanced culture and maintain the orientation of socialist advanced culture.

\subsection{Big data culture contributes to the rapid development of cultural industry}

China is a large country of abundant cultural resources, and big data provides a new way for their industrialization. Big data can be used to strengthen and expand a number of key scientific and cultural enterprises and cultural bases, and to actively develop new types of big data cultural businesses. In order to rejuvenate the big data cultural market, it is important to lay emphasis on the innovation of cultural model, to provide the big data support for the cultural industry, and to foster the cultural industry to become the pillar of the national economy as soon as possible.

\subsection{Big data culture helps to drill cultural diffusion ability}

Big data can further multiply the channels of cultural communication, enrich the means of cultural communication, help to construct the modern communication system of advanced technology, and enhance the implication of advanced culture. In the process of building a strong cultural power, the value of big data culture should be fully represented, the competitiveness and influence of big data cultural products in China should be enhanced, and China's big data culture should be actively open to the world as a leading power.

\section{Summary}

The strategy of cultural power needs the support of big data culture, and big data culture is integral to maintaining the advancement of Chinese culture. This is not only conducive to the construction of socialist culture with Chinese characteristics, but also to the continuous cultural innovation. Maintaining advancement of socialist culture with Chinese characteristics is also conducive to continuously enhancing the scientific and technological elements of Chinese culture, further liberating and developing cultural productivity, and enhancing the international influence of Chinese culture. 


\section{References}

[1] R.F. Sun, The road to building a strong socialist culture, Beijing: CPC History Publishing House(China), pp. 2, 2012.

[2] Y.M. Lian, The data revolution, Beijing: Contemporary Chinese Publishing House(China), pp. 4, 2016. 